University of Nebraska - Lincoln

DigitalCommons@University of Nebraska - Lincoln

Faculty Publications, UNL Libraries

Libraries at University of Nebraska-Lincoln

$1-29-1989$

\title{
Silica Exposure and Silicosis among Ontario Hardrock Miners: II. Exposure Estimates
}

D. K. Verma

Occupational Health Program, McMaster University, Hamilton, Ontario, vermadk@mcmaster.ca

A. Sebestyen

Occupational Health Program, McMaster University, Hamilton, Ontario

J. A. Julian

Occupational Health Program, McMaster University, Hamilton, Ontario

D. C. F. Muir

Occupational Health Program, McMaster University, Hamilton, Ontario

H. Schmidt

Occupational Health Program, McMaster University, Hamilton, Ontario

See next page for additional authors

Follow this and additional works at: https://digitalcommons.unl.edu/libraryscience

Part of the Library and Information Science Commons

Verma, D. K.; Sebestyen, A.; Julian, J. A.; Muir, D. C. F.; Schmidt, H.; Bernholz, Charles D.; and Shannon, H. S., "Silica Exposure and Silicosis among Ontario Hardrock Miners: II. Exposure Estimates" (1989). Faculty Publications, UNL Libraries. 103.

https://digitalcommons.unl.edu/libraryscience/103

This Article is brought to you for free and open access by the Libraries at University of Nebraska-Lincoln at DigitalCommons@University of Nebraska - Lincoln. It has been accepted for inclusion in Faculty Publications, UNL Libraries by an authorized administrator of DigitalCommons@University of Nebraska - Lincoln. 


\section{Authors}

D. K. Verma, A. Sebestyen, J. A. Julian, D. C. F. Muir, H. Schmidt, Charles D. Bernholz, and H. S. Shannon 


\title{
Silica Exposure and Silicosis among Ontario Hardrock Miners: II. Exposure Estimates
}

\author{
D. K. Verma, PhD, CIH; A. Sebestyen, BSc; J. A. Julian, MMath; \\ D. C. F. Muir, PhD, FRCP; H. Schmidt, BSc; C. D. Bernholz, MA; \\ and H. S. Shannon, PhD \\ Occupational Health Program, McMaster University, Hamilton, Ontario, Canada
}

Accepted for publication December 12, 1988.

\begin{abstract}
An epidemiological investigation was carried out to determine the relationship between silicosis in hardrock miners in Ontario and cumulative exposure to silica (free crystalline silica-a quartz) dust. This second report describes a side-by-side air-sampling program used to derive a konimeter/gravimetric silica conversion curve. A total of 2,360 filter samples and 90,000 konimeter samples were taken over 2 years in two mines representing the ore types gold and uranium, both in existing conditions as well as in an experimental stope in which dry drilling was used to simulate the high dust conditions of the past. The method of calculating cumulative respirable silica exposure indices for each miner is reported.
\end{abstract}

Key words: silica, konimeter, respirable dust, quartz, konimeter-gravimetric conversion

\section{INTRODUCTION}

This is the second paper of a series describing an epidemiological study into the relationship between the development of silicosis in miners and dust exposure in hardrock mines in Ontario. The basic methodology and cohort definitions are given in part I [Muir et al., 1989a] and the dose-response relationship in part III [Muir et al., 1989b].

An accurate assessment of dose is critical in a study aimed at deriving a dose-response relationship and is especially difficult in a historical study. In the mines under study, exposure measurements had been taken over 40 years (1940-1982) with konimeters and expressed in particles per cubic centimeter of air (ppcc). Early measurements were often taken sporadically to evaluate engineering methods rather than to measure health risk. Also, different methods of sampling and analysis were used over the years. Most importantly, for our dose estimates, we wanted respirable silica exposure as measured by the modern-day gravimetric method (e.g., cyclone and filter). This required the conversion of the standardized, historical dust counts into equivalent gravimetric measures in milligrams of silica per cubic meter $(\mathrm{mg} / \mathrm{m} 3)$ of air. 


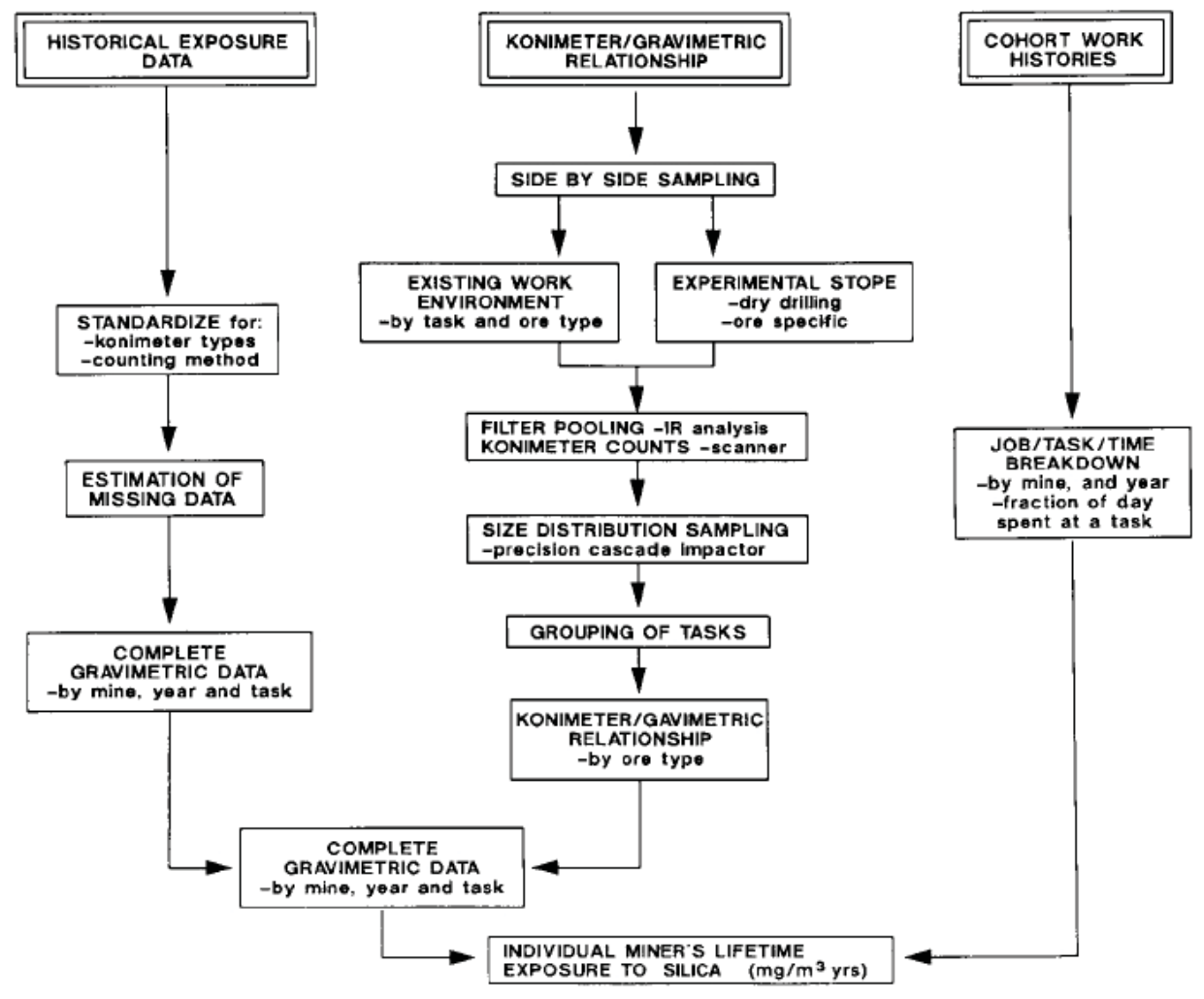

Fig. 1. Flow diagram showing the method for estimating a miner's lifetime silica exposure $\left(\mathrm{mg} / \mathrm{m}^{3}\right.$ years).

Part of the difficulty in obtaining a konimeter to gravimetric conversion is that the two techniques measure entirely different parameters. The konimeter measures the number of particles per unit volume of air with a collection efficiency that has only recently been determined [Sebestyen et al., 1987]. On the other hand, the cyclone and filter with infrared (IR) analysis measures the mass of respirable silica per unit volume of air.

The objectives of the exposure estimation as described in this paper were: 1) to obtain a complete set of exposure data for all the tasks during the years of operation of the mines in the study from 1940 to $1982 ; 2$ ) to obtain a relationship between konimeter counts and gravimetric silica concentration; and 3) to calculate the lifetime exposure to respirable silica dust of each miner in the cohort.

\section{MATERIALS AND METHODS}

The estimation of an individual miner's lifetime exposure to silica in $\mathrm{mg} / \mathrm{m}^{3}$ years required the linking of three separate lines of investigation, as shown in Figure 1. Historical dust data needed to be obtained from several sources. Quantitative data, in terms of konimeter counts, were used rather than the subjective opinions of senior mine employees, which are considered a poor estimate of historical conditions [Kromhout et al., 1987]. 
Any missing data were imputed from existing quantitative data. A konimeter-to-gravimetric relationship was required to convert the historical data into gravimetric units. Lastly, the work history of each member of the cohort was needed with each job subdivided into its component tasks. The cumulative dust levels could then be computed by assigning times to the tasks performed during each shift.

\section{Historical Dust Exposure Data}

In Ontario mines, dust concentrations were measured historically with a konimeter, an instantaneous dust sampler having a sampling duration of approximately one-third of a second. The collected dust sample was counted under a microscope and expressed as the number of particles per unit volume of air (particles per cubic centimeter). The earliest available konimeter dust data in Ontario date back to 1940. However, the data of the 1940s and 1950s were very sparse and incomplete. A reasonably complete set of konimeter counts (K-counts) is available starting in 1959. In 1959, the Mines Accident Prevention Association of Ontario (MAPAO) instituted a semiannual dust survey in Ontario mines. The reports were consistent from mine to mine with regard to the major dust-making tasks such as drilling, mucking, and dumping but were less consistent for minor tasks such as washing and scaling. The surveys were designed to assist in engineering dust control methods rather than to estimate individual exposures.

The konimeter counts were obtained from two sources: the MAPAO, through the semiannual reports from 1959 on; and prior to 1959, from the individual mines, via MAPAO consultation reports and air-sampling records from the mines' environmental engineers.

Seventy-four historical mining tasks were originally compiled from the various sources (Table I); these were subsequently grouped into 29 tasks because many were identical or similar in operation. Also, tasks were grouped to match the detail available in the work histories. For example, if it were known that the miner worked as a raise driller, the raise-drilling environmental data were used in his dose calculation. If his job was listed as "drilling," the mean of all the drilling data, including raise, stope, shaft, and heading where available, was used as his dust exposure. This was also done for the task of scraping. LHD, in the historical tasks, refers to Load-Haul-Dump equipment operation. These groupings were verified by experts at the MAPAO as well as by engineers and miners employed at the mines in the study. The approach of grouping exposures has been used in previous studies [Dement et al., 1983; Corn and Esmen, 1979].

Each mine job was divided into one or more of these 29 tasks for a typical 8-hour shift. The silica concentration for a task in the year and mine of interest was then combined with the task times and work history data to produce a cumulative silica exposure for each miner.

The uranium mines in Elliot Lake began production in 1957, from which time the MAPAO's semiannual reports recorded the mines' dust conditions. The gold mines of Timmins and Kirkland Lake were in production before the semiannual reports were instituted. Historical konimeter counts for the years 1940-1959 were available only as measured by each mine on an irregular basis, although most mines had some environmental data for this time period.

Environmental data for the mines were summarized in the following manner: the spring and fall konimeter counts for each year of the semiannual survey were averaged 
TABLE I. Assignment of Similar Historical Task(s), as Specified by Various Ontario Mines, Into Single Task Categories for Exposure Ascertainment

\begin{tabular}{|c|c|}
\hline Tasks & Historical tasks \\
\hline 1. Assay lab & $\begin{array}{l}\text { Assay lab, general atmos.; cleaning floor; assay office } \\
\text { (blowing samples with compressed air); crushing samples; } \\
\text { handling samples; pulverizing samples; riffling samples; } \\
\text { grinding ore }\end{array}$ \\
\hline 2. Drilling & Drill heading; drill raise; drill shaft; drill stope \\
\hline 3. Drilling heading & Drill heading \\
\hline 4. Drilling raise & Drill raise \\
\hline 5. Drilling shaft & Drill shaft \\
\hline 6. Drilling stope & Drill stope \\
\hline 7. Dumping & Dumps and passes; dumping at grizzlies; dumping \\
\hline 8. Filling stope & Filling stope \\
\hline 9. Level work/Travelling & Main drifts and cross-cuts \\
\hline 10. Mill work & $\begin{array}{l}\text { Screening (ore); transferring (ore); general atmosphere, mill; } \\
\text { concentrate area; disc filters; drum filters; dry mills and } \\
\text { processes; mill bins; open tanks; refinery; wet mills and } \\
\text { concentrator }\end{array}$ \\
\hline 11. Mucking & $\begin{array}{l}\text { Handling broken rock-heading, raise, stope; mucking draw } \\
\text { points; mucking (LHD); mucking (scrams); muck mach.; } \\
\text { LHD and scraping stope; LHD cavo; LHD stope; LHD } \\
\text { stope (muck mach.); loading; load stope }\end{array}$ \\
\hline 12. Mucking heading & Load heading \\
\hline 13. Mucking raise & Load raise \\
\hline 14. Production work area & $\begin{array}{l}\text { Air leaving: handling broken rock-heading, raise, stope; } \\
\text { drilling-heading, raise, stope, shaft; loading; raises } \\
\text { (scraping); stopes--scraping, LHD, LHD stope; muck. } \\
\text { machine }\end{array}$ \\
\hline 15. Pulling chutes & Pulling chutes \\
\hline 16. Sampling & Sampling \\
\hline 17. Scraping & $\begin{array}{l}\text { Scraping; scraping (stope); scraping (raise); slushing-raise; } \\
\text { loading shaft }\end{array}$ \\
\hline 18. Scraping raise & Scraping (raise); slushing (raise) \\
\hline 19. Scraping stope & Scraping; scraping (stope) \\
\hline 20. Set charge & Production area work \\
\hline 21. Shaft and stations & Shafts and stations \\
\hline 22. Skiptending & $\begin{array}{l}\text { Shaft loading pockets (outside booth); skiptender's booth } \\
\text { (inside) }\end{array}$ \\
\hline 23. Surface (dusty) & $\begin{array}{l}\text { Cleaning floor, assay off.; cleaning floor, crushing plant; } \\
\text { shops }\end{array}$ \\
\hline 24. Surface (non-dusty) & Give dust exposure of 0 \\
\hline 25. Surface crushing & $\begin{array}{l}\text { Crushing (ore); gencral atmosphere, crushing plant; } \\
\text { conveying and transfers; crushing and screening; primary } \\
\text { crushing; secondary crushing; secondary crushing and } \\
\text { screening; screening ore; cleaning floor, crushing plant }\end{array}$ \\
\hline 26. Timbering & Timbering \\
\hline 27. Trammer/trollcy operation & Tramming; main drifts and cross-cuts \\
\hline 28. Underground crusher operation & Underground crusher operation \\
\hline 29. Scaling & Scaling stope; scaling \\
\hline
\end{tabular}

for each mine's operations. Thus, mean konimeter counts by mine, task, and year were obtained. his was also done with the presemiannual report konimeter data available from each mine. In total, over 210,000 konimeter counts were available for averaging, providing $58 \%$ of the mine/task/year environmental data. Several methods of dealing with miss- 


\begin{tabular}{|c|c|c|c|c|c|c|c|}
\hline \multicolumn{8}{|c|}{$\begin{array}{c}\text { INDUSTRY } \\
\text { (Mean PPCC) }\end{array}$} \\
\hline TASK & \multicolumn{5}{|c|}{ YEAR } & 6 & SUM \\
\hline 01 & 475 & 475 & 430 & 382 & 250 & 183 & 1290 \\
\hline 02 & 288 & 449 & 330 & 312 & 302 & 259 & 1940 \\
\hline 03 & 879 & 738 & 732 & 430 & 124 & 70 & 70 \\
\hline 04 & 370 & 392 & 379 & 290 & 130 & 108 & 1000 \\
\hline \multicolumn{8}{|c|}{$\begin{array}{c}\text { MINE "X" } \\
\text { (Mean PPCC) }\end{array}$} \\
\hline TASK & \multicolumn{5}{|c|}{ YEAR } & 6 & SUM \\
\hline 01 & 4201 & 420 & 4352 & 450 & 370 & 250 & 1490 \\
\hline 02 & 300 & 380 & 320 & 300 & 280 & 150 & 1630 \\
\hline 03 & $967^{3}$ & 812 & 805 & 473 & 136 & 120 & 120 \\
\hline 04 & 450 & 430 & $565^{4}$ & 432 & 300 & 310 & 1490 \\
\hline $\begin{array}{l}\min \\
\text { tas }\end{array}$ & ati & 4 & & & & & 4730 \\
\hline
\end{tabular}

Fig. 2. Extrapolation of missing mine-specific konimeter counts by using historical counts by industry (ore type) and by mine.

ing data have been suggested [Checkoway, 1986, 1987; Dement et al., 1983], but our approach was to impute the values from the strong foundation of existing data.

The historical K-counts for each mine within each "industry" (gold or uranium) were summarized as a two-dimensional table of 29 tasks (rows) and 43 years (columns) from 1940 to 1982. Figure 2 shows an industry and a mine table. Although the number of missing cells was small in the industry table (15\%), we employed a general set of rules to generate the missing K-counts. For single missing cells in the interior of the table (that is, not at the ends of the row), the midpoint or mean of the counts for the years bordering or adjacent to the empty cell was used. For missing counts at either end of the row (i.e., years), the adjacent or closest available cell was used to complete the row (endpoint method). When two or more interior values were missing, linear trend lines were computed between the existing counts bordering the missing year intervals. For example, a row with a 400 count followed by three missing values, followed by an 800 count, would be replaced by the series " $400,500,600,700,800$." This method was also used to estimate a series of missing end values for the later years since our current field sampling provided good estimates for the years following the end of the study.

The imputation technique for the task by year table for the individual mines was similar. Figure 2 gives examples of the four methods of estimation. Missing single interior and end values were estimated in exactly the same manner. When intervals of more than 1 year were missing, the industry table was employed to estimate the value. If four or more $\mathrm{K}$-counts for a task were available, the missing cells were estimated by applying a taskscaling factor to the task-specific industry count for that year. This factor is computed as 
the ratio of the mean task-specific counts over all available years for that mine relative to the industry. When less than 4 years of mean counts are available for a task, a mine-scaling factor was applied to the industry values. This factor is calculated as the ratio of the mean counts over all available tasks and years for that mine compared to the industry.

Tasks restricted to surface operations were considered to be nondusty and therefore had negligible K-counts. A background count of 25 ppcc was assigned to these tasks for all years. The rules for imputing the K-count data are outlined in Figure 2.

Over the years and between the mines, there was a substantial difference between the type of konimeter used and the method of counting. Thus, the konimeter data from the various mines were standardized to the Gathercole konimeter as counted by the electronic scanner at the MAPAO [Flint, 1965; Chmara, 1969].

Standardizing for type of konimeter. Side-by-side comparisons of four konimeters used in Ontario were carried out in both a gold and an uranium mine [Verma et al., 1987]. The Devers konimeter, the Witwatersrand, and the Witwatersrand with preimpactor were compared to the Gathercole, which was the principal instrument used in Ontario. The historical konimeter counts were transformed to Gathercole equivalent counts according to the linear regression equation obtained for each ore type.

Standardizing for different counters and for manual vs. scanner counting. A konimeter counting comparison was carried out at the MAPAO offices in North Bay. Four experienced counters who had provided much of the original konimeter data for several mines in the study were compared to each other and to the scanner. Four slides, each containing 28 konimeter spot samples, were counted by all the participants. To avoid a microscope bias, each man counted an equal number of spots on each of the four microscopes used in the comparison.

The results showed a significant $(\mathrm{p}<.05)$ difference in particle count from one counter to the next. Since the reader of a historical dust count is usually not known, a general man-to-scanner conversion was obtained by combining the results of the four counters in a single regression equation:

$$
\text { Scanner }=806-444 \log _{\mathrm{e}}(\text { Man })+63\left[\log _{\mathrm{e}}(\text { Man })\right]^{2}(1)
$$

The $\mathrm{R}^{2}$ for the curve was $87 \%$. A plot of the scanner vs. man relationship is shown in Figure 3 . The accuracy of a counter was examined by having him recount a sample of konimeter spots. Although some variability existed between the original count and the recount for all readers, no significant difference was observed. Historical data prior to 1967 when the scanner came into operation were counted manually to a maximum count of 2,000 ppcc. Exact counts above 2,000 were not possible and were subsequently reported as $2,000+$. The scanner has effective lower and upper count limits representing dust concentrations of 50 and 1,000 ppcc, respectively. Counts higher than 1,000 are reported as $1,000+$ and counts lower than 50 as $<50$.

In the exposure calculations, all 2,000+ manual counts were treated as 2,000; $1000+$ scanner counts were treated as 1,000 ; and $<50$ scanner counts were converted to 25 ppcc. This could lead to an underestimate of the actual level of dustiness; however, the proportion of data that fell into the $2,000+$ or $1,000+$ category was very small (less than $2 \%$ ), so we believe that the underestimate was small. All manual counts were then converted to scanner-equivalent counts by using equation 1 . 

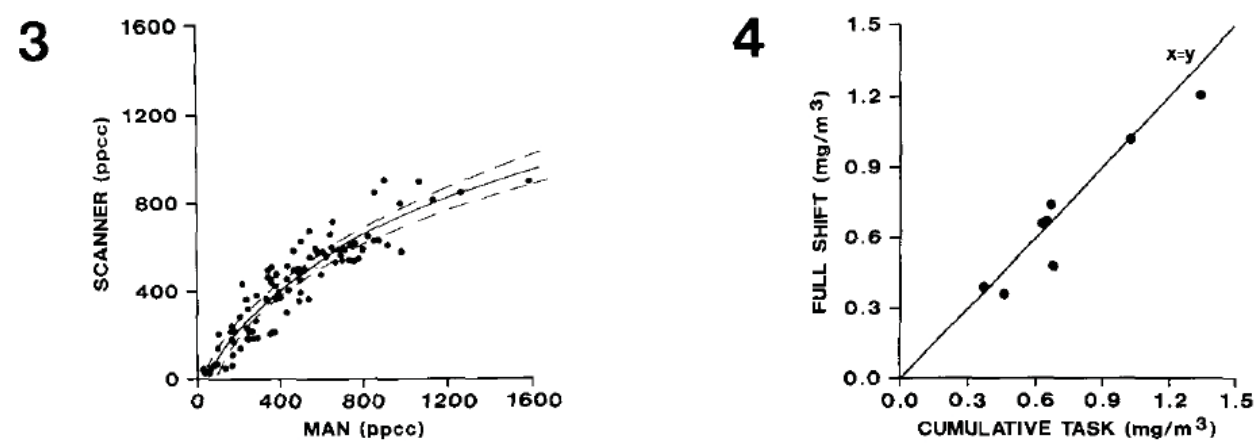

Fig. 3. The relationship between scanner-counted konimeter spots and man-counted spots.

Fig. 4. A comparison of full-shift gravimetric sampling to cumulative task sampling over the shift.

\section{Konimeter to Gravimetric Relationship-Sampling and Analysis Protocol}

A konimeter-to-gravimetric relationship was obtained by comparing a Gathercole konimeter to a constant-flow pump with nylon cyclone-filter assembly in a side-by-side sampling program. A total of 2,360 filter samples and 90,000 konimeter samples were taken over 2 years in two mines representing the ore types gold and uranium, both in existing conditions as well as in an experimental stope in which dry drilling was used to simulate the high dust conditions of the past.

The respirable dust was sampled onto either a $0.8 \mathrm{pm}$ mixed cellulose ester or polyvinyl chloride (PVC) filter using a $10 \mathrm{~mm}$ nylon cyclone assembly. Air was drawn through the assembly, at a flow rate of 1.7 liters/minute (lpm) using a constant-flow personal sampling pump (Dupont P2500) to match the American Conference of Governmental Industrial Hygienists (ACGIH) respirable dust criteria [Aerosol Technology Committee, 1970]. Silica analysis of the dust was done by the infrared spectrophotometric (IR) method [NIOSH, 1984; Dodgson and Whittaker, 1973]. The IR method permits the pooling of filters when individual filters do not have sufficient silica for analysis.

Konimeter slides were prepared for sampling by the procedure outlined in van Nierop [1973] with some modifications. In Ontario, the standard procedure is to apply the adhesive by flooding one side of the slide with a $2 \%$ Vaseline/xylene solution instead of dipping and slowly withdrawing the slide as suggested by van Nierop. The slide is subsequently tipped on its end to drain off the excess solution and allowed to dry. All of the samples were sent to the MAPAO for counting with the electronic scanner.

The sampling program was designed to encompass all variables which were thought likely to affect the konimeter-to-gravimetric relationship. Since they have very different acceptance curves [Lippmann and Harris, 1962; Aerosol Technology Committee, 1970; Sebestyen et al., 1987] and measure different fractions of the cloud, the conversion was thought to be dependent upon the size distribution of the airborne dust. This is likely a function of how the dust is produced or the elapsed time since production and thus is "task" dependent. For this reason, and because the historical data are task-specific, the sampling and analysis were done on a task basis. 
A konimeter-to-gravimetric relationship is also influenced by the mineral composition of the dust. The preparation of the konimeter samples leaves particles of acid-insoluble minerals of which only a small proportion is silica. A gravimetric sample with analysis by IR, on the other hand, measures only the weight of silica. We have attempted to separate dusts of different mineral composition by analyzing the samples from the gold and the uranium mine separately.

Furthermore, the konimeter is an instantaneous sampler while the cyclone is a longterm sampler. The gravimetric sampler masks fluctuating dust concentrations within a task because the results are a time-weighted average over a long period. The konimeter measures the dust concentration at the instant of sampling and so is subject to wide variability depending on the time of sampling. To account for the short sampling duration of the konimeter, three konimeter samples were taken in rapid succession every 15 minutes in the side-by-side comparison. The mean of the three spots represented one reading, and the gravimetric sample was subsequently compared to the mean of all 15-minute readings taken during the sampling period.

Jobs were subdivided into 29 tasks, for which historical dust measurements were available. A minimum of 15 job titles covered the 29 tasks, but because a task may be common to many jobs, several jobs were sampled to obtain an accurate representation of a task.

Each dust-sampling technician sampled one miner for a week, obtaining measurements of all the tasks done by that miner. A job was selected for sampling, and the man to be sampled was selected from a roster of miners performing that job. Occasionally, since many tasks were short in duration, sampling continued into a second week or more with new subjects being sampled for each new week. As a convenient estimate of the amount of sampling done on a task, the volume of air sampled for a task was accumulated day by day until approximately 5,000 liters of air had been obtained. The filters were subsequently weighed to determine the total amount of dust sampled for each task. It was hoped that this would provide enough dust to give at least five measurements of silica after the pooling of filters and analysis. For some low dust tasks, more sampling was required.

A sampling technician accompanied the miner at all times. The miner was fitted with a gravimetric cyclone sampler, and sampling commenced when he entered the mine. This filter was worn until he reached his workplace. The "travelling" task filter and cyclone assembly were then removed and stored, and the miner was fitted with another filter/cyclone assembly for the next task to be performed. If the task was repeated during the shift, the same assembly was used to continue sampling that task. In this manner, gravimetric samples for all the identified tasks were collected. In order to obtain corresponding "time-weighted average konimeter counts," three konimeter spots were taken close to the miner every 15 minutes by the technician with both the task and the time noted for each sample.

It will be evident from this description that the gravimetric samples consisted of a series of short-term samples corresponding to the duration of each separate task rather than the more familiar full-shift, 8-hour sample. The rationale for this strategy lay in the possibility that the konimeter-to-cyclone relationship might be task specific. Analysis of the silica content of the small samples obtained in this way was limited by the sensitivity of the instrumentation, and it was necessary to pool filters until a combined weight of 1.5-2.0 mg of dust was present. In order to relate the widest possible range of konimeter counts to the corresponding gravimetric silica measures, the following protocol was 
(A) DRILLING SCHEDULE

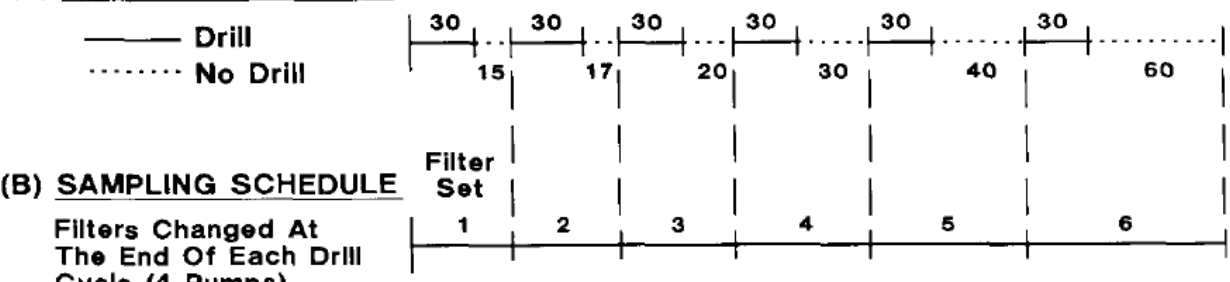
Cyclo (4 Pumps)

\section{Fllters Changed At The Start Of Each Drll Cycle (4 Pumps)}

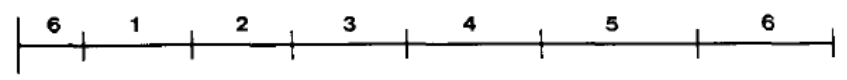

\section{Full Shift Sampling} (2 Pumps)

\section{Driling/No Driling (4 pumps)}

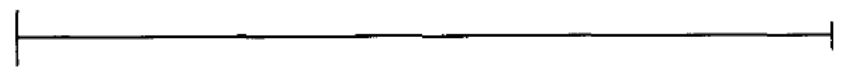

Fig. 5. Protocol for the dry drilling experiment to obtain a konimeter-to-gravimetric relationship at high dust levels.

adopted. Filters from each task were first ranked according to the corresponding mean konimeter count. Filters were then pooled in sequence until 1.5-2.0 mg of dust was present. Clearly, fewer filters were required to achieve this total when the corresponding konimeter counts were higher than when they were low. The pooled set was then analyzed by IR, and the resultant silica value was related to the mean konimeter counts for that set.

Samples obtained from different ore types (gold and uranium) were analyzed separately. The validity of determining full-shift gravimetric exposure estimates by cumulative short-term samples was tested by equipping a worker with two cyclones, one sampling on a series of short task periods and the other on a normal full-shift basis. It was found that the two estimates of full-shift exposure were in good agreement (Fig. 4).

\section{Experimental Stopes-Dry Drilling}

Because of improved ventilation and dust suppression techniques, the high dust exposures encountered in the past are virtually nonexistent today. This made it impossible to compare konimeter and gravimetric measurements at high dust concentrations. To overcome this problem, high dust concentrations were generated in an experimental stope by dry drilling. Two experiments were conducted, one in the gold mine and the other in the uranium mine. The study was undertaken with the cooperation of the miners, who were provided with full respiratory protection.

A protocol was designed to produce maximum information. Three konimeter spots were taken every 5 minutes in proximity to a set of 12 gravimetric samplers. The drilling and sampling schedule, shown in Figure 5, was synchronized to give filter samples which corresponded to a range of average konimeter counts and which contained varying amounts of dust. Filter samples were removed and replaced with new filters at the prede- 


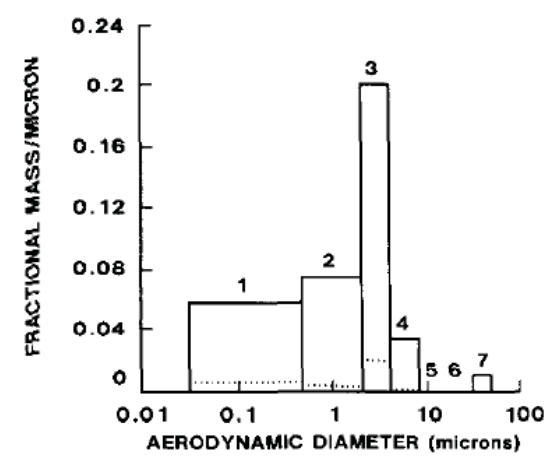

Fig. 6. Airborne particle size distribution for the task of mucking (seven size fractions). Inorganic dust, bars; silica, dots.

termined intervals. Duplicate samples were taken, in most cases resulting in a total of 58 separate filters for the day. Konimeter spots were counted by the scanner. Spots reading over 1,000 ppcc were recounted manually by an experienced counter and converted back to scanner equivalent counts by the man/scanner equation. This provided accurate estimates of konimeter concentrations at the upper limit of resolution by the scanner.

As in the analysis of the task samples, filters were ranked according to the corresponding average konimeter count and pooled to a total of $1.5-2.0 \mathrm{mg}$ of dust. This resulted in 33 konimeter-to-gravimetric comparisons for the gold mine ranging from average konimeter counts of 403-1,538 ppcc. The uranium mine experimental stope gave 22 konimeter-to-gravimetric comparisons ranging from average konimeter counts of 196 to 796 ppcc.

\section{Particle Size Distribution Sampling}

Airborne dust samples were taken for each task with a high volume precision cascade impactor which fractionated the dust into seven ranges of aerodynamic particle sizes from submicron to $32 \mu \mathrm{m}$ and larger. It was hoped that enough dust could be collected even for the low dust tasks to provide a size distribution of the airborne dust and of the size distribution of the underlying airborne silica dust.

The impactor, built in West Germany by Retsch Instruments, operated at a flow rate of 40 liters/minute and separated the respirable particles into five overlapping size ranges [Emmerichs and Armbruster, 1981]. The pump which normally provided the air flow to the instrument operated on an electrical supply which was not available underground. Since the only power universally available in all working areas of a mine was a supply of compressed air, a unique system was designed by using a Venturi to provide the 40 liters/ minute suction through the Retsch Instrument. The details of the system will be described in a separate paper.

The size distributions of the different tasks were compared, but no statistical difference was found $(\alpha=.05)$. Therefore, all tasks for an ore type were combined into one konimeter to gravimetric relationship. An example of the airborne dust and underlying silica dust size distribution for mucking is shown in Figure 6. The histogram has been standardized to show mass of dust per micron [Hinds, 1982]. 


\section{Cohort Work Histories}

Work histories for each miner were obtained from the files of the provincial Workers' Compensation Board. Each entry on the record consisted of a start-date, a mine, and the job held. Since the exposure concentrations for each mine and year were estimated by task, not job, each job at every mine had to be broken down into its component tasks. Each task was then assigned a time, based on the number of hours spent at the task in an eight hour shift for that mine and era.

The "job/task/time" breakdown for each mine was obtained by interviewing senior employees of the mine who could recall the early work practices. On occasion, additional employees were interviewed at a mine to verify job breakdowns and to supply missing information. A job/task/time breakdown may have remained constant over the productive life of a mine or it may have changed over time with the introduction of new technology or with a change of work practices. In this case, the breakdown was changed accordingly.

The cohort inclusion criteria permitted up to $20 \%$ work experience in Ontario mines other than those in the study. These mines were coded as "other gold," "other uranium," and "nongold and nonuranium." The jobs were subsequently given a task/time breakdown based on that job within study mines of the same ore type. Nongold and nonuranium jobs were given a general industry breakdown.

The exposures assigned to these tasks were taken from the corresponding ore type industry exposure table. Exposures for nongold and nonuranium, predominantly nickel, were given a value of $50 \%$ of the gold industry task values. The factor of $50 \%$ was based on the evidence that the airborne dust in nickel mines has approximately one-third the silica content of dust in gold mines, whereas the dust levels, in terms of ppcc, were higher or equivalent over the years for which measurements were made.

Jobs in a man's work history were broken down to their component tasks along with the times spent at those tasks. These were then related to the gravimetric concentration for a specific mine and year to calculate a worker's cumulative lifetime dose of silica.

\section{RESULTS}

For the derivation of a konimeter-to-gravimetric relationship, a total of 137 observations for gold mines and a total of 84 observations for the uranium mine were obtained. The gravimetric value of each point represents the results of the silica analysis as described above. The corresponding konimeter value represents the mean of all the konimeter counts taken during the time that the filter sample or samples were being taken.

An important consideration in comparing the two methods is the random measurement error. Gravimetric sampling is associated with high analytical errors for small amounts of silica dust (less than $10 \mu \mathrm{g}$ ). On the other hand, the konimeter is least reliable for high dust counts. Since the reliability of particle counting relies upon the ability to observe independent spots, the error in counting should be quite minimal at the low end (less than 200 ppcc) but increase rapidly with poor reliability in the range above 800 ppcc. This effect is enhanced even more when using the electronic scanner. Since gravimetric measurements are more precise than the konimeter, it was felt appropriate to model the konimeter as a function of the gravimetric values for regression purposes. Again, since the error seemed to vary over the range of observations for the konimeter, the number of konime- 

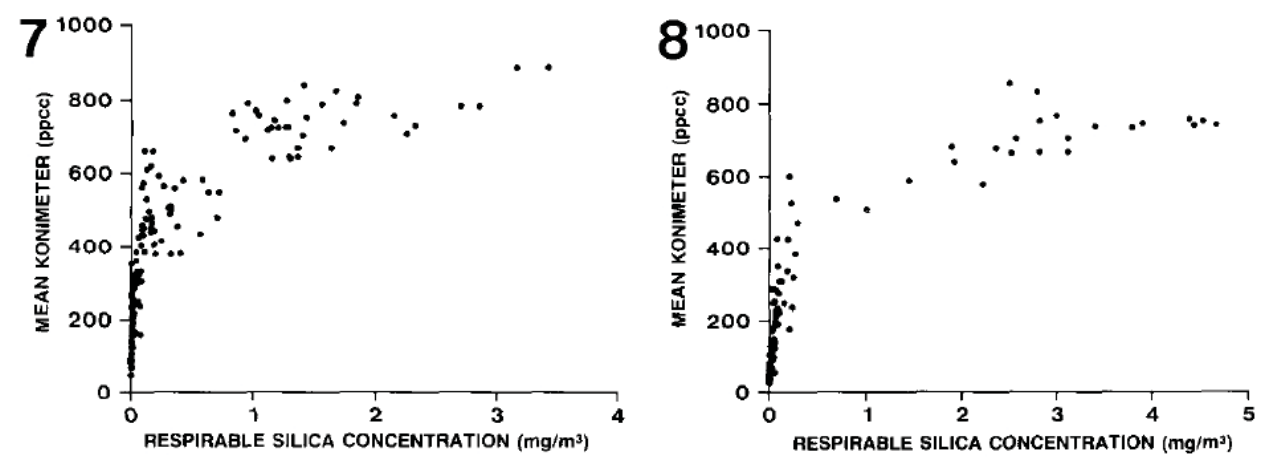

Fig. 7. The relationship between mean konimeter counts and respirable silica concentration for samples taken in gold mines (mean silica concentration in the respirable dust- $6.0 \%$ ). Fig. 8. The relationship between konimeter counts and respirable silica concentration for samples taken in uranium mines (mean silica concentration in respirable dust- $8.4 \%$ ).

ter-spots included in the arithmetic means was used to weight the regression fitting.

Initially, a linear model was considered, but plots of the data by ore type displayed clear nonlinearity. Some of the task-specific data did exhibit linearity, but the range of observations was quite limited. The plots of the data (shown in Figs. 7, 8 for the gold and uranium mines, respectively) suggested a number of possible functional forms. The contenders would have to meet the following conditions: they would have to have a continuous monotonic increasing function, pass through the origin, apply to all ore types and tasks, and involve relatively few terms.

Linearizing transformations of either or both variables, quadratic, exponential type, and hyperbolic trigonometric functions, were considered by evaluating residual plots. The most satisfactory function contained both linear and exponential terms:

$$
\mathrm{K}=\beta_{0} \cdot\left(1-\exp \left(\beta_{1} \cdot \mathrm{G}\right)\right)+\beta_{2} \mathrm{G}
$$

where $\mathrm{K}$ and $\mathrm{G}$ represent the konimeter and gravimetric silica concentrations, and $\beta_{0}, \beta_{1}$, and $\beta_{2}$ are the modelling parameters to be estimated.

This nonlinear model was then fitted to the entire data set by employing dummy variables to account for ore type (gold or uranium), job tasks (various), and their interactions. No statistical differences were found among individual tasks or among tasks grouped by similar size distributions as we had believed. A possible explanation could be that the ventilation is sufficiently strong to eliminate the changes in size distribution during time. However, there were strong differences between ore types. A summary of the estimates appears in Table 11. The fitted curves for both uranium and gold mining fit well with no overlap between them.

Since it was impossible to invert the function algebraically, we generated a table of gravimetric silica values for unit measurements in konimeter count densities ranging from 0 to 1,200 ppcc. The resultant curves are displayed in Figure 9. Appendix A shows a table of conversion from gravimetric to konimeter measurements using the parameter estimates given in Table II. 
TABLE II. Parameter Estimates for the Gravimetric-toKonimeter Conversion Curves by Ore Type*

\begin{tabular}{llc}
\hline & \multicolumn{1}{c}{ Gold } & Uranium \\
\hline No. of data pairs & 137 & 95 \\
$\beta_{0}$ (se) & $459(19.3)$ & $437(31.1)$ \\
$\beta_{1}(\mathrm{se})$ & $-27.4(2.81)$ & $-9.25(1.18)$ \\
$\beta_{2}$ (se) & $159(17.2)$ & $86.3(12.0)$ \\
\hline
\end{tabular}

*Parameter estimates are given for the conversion of gravimetric concentrations in $\mathrm{mg} / \mathrm{m}^{3}$ to konimeter counts in ppcc.

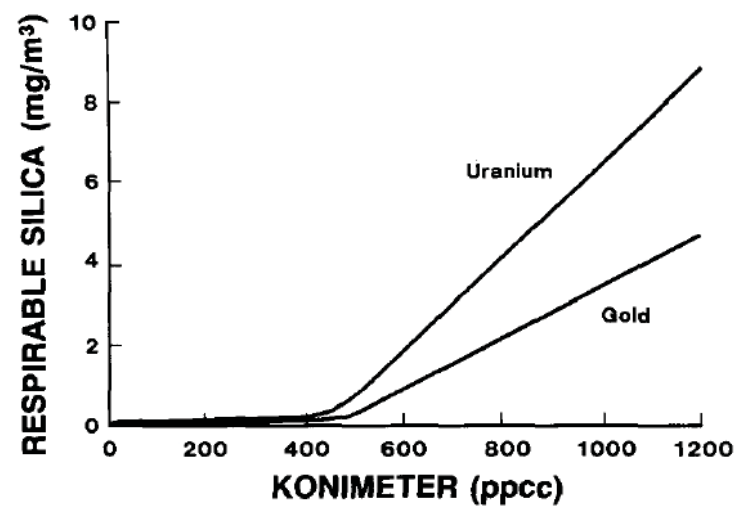

Fig. 9. The fitted nonlinear model inverted to show respirable silica concentration (gravimetric) as a function of the konimeter count for both gold and uranium mines.

\section{DISCUSSION}

The conversion of particle counts into gravimetric units has been attempted in several investigations, and it has been a major component of a number of epidemiological studies in coal mining, hardrock mining, and in surface industries [Cartwright, 1965a,b; Jacobson and Tomb, 1967; Sutton and Reno, 1968; Chamberlain et al., 1971; Dodgson et al., 1971; Jacobsen et al., 1971; Ayer et al., 1973; Gibbs and Lachance, 1974; Thériault et al., 1974; Walton, 1982; Davis et al., 1983; Rice et al., 1984]. In these studies, particle counts were obtained by impinger or thermal precipitator while gravimetric measurements were obtained by using an MRE sampler or a cyclone. Chmara and Knight [1978] attempted to derive a relationship between full-shift average konimeter counts and fullshift gravimetric respirable dust concentration. Their results were inconclusive because their measurements did not cover the full range of konimeter counts and because their sample size was small. The present results appear to be the first to relate konimeter counts to gravimetric silica equivalent over a broad range of values. It may be possible to utilize these results in other industries in which konimeters have been used in the past, provided that account is taken of the mean silica and inorganic dust (rock dust) content of the respirable dust. In the uranium mine in our study, the mean respirable silica concentration was $8.4 \%$. In the gold mine, it was $6.0 \%$ but may have been higher in previous years when dry 
drilling was used. There is unlikely to be a simple relationship between the silica content of the respirable dust and the konimeter/gravimetric conversion ratio. Although the mean silica content of the respirable dust in the uranium mine was $50 \%$ greater than that of the gold mine, the distance between the curves shown in Figure 9 is almost twofold.

The main difficulty throughout the study has been to develop a system for obtaining sufficient silica for analysis, and this could only be achieved by combining filters. Fullshift sampling would have been simpler, but this approach could not be adopted because historical konimeter counts were carried out in relation to identified tasks and were unsuitable for estimating full-shift average exposures.

The konimeter-to-gravimetric relationships of Figure 9 were used to convert the "historical task specific konimeter" counts into equivalent gravimetric concentrations. By using the "time task" breakdown of the "cohort work history" and by applying the converted gravimetric concentrations to each task, a lifetime cumulative dose of respirable silica for each miner in the cohort was calculated. The lifetime dose has been used in the derivation of the relationship between respirable silica concentration in $\mathrm{mg} / \mathrm{m}^{3}$ and the radiological silicosis described in the third part of our report [Muir et al., 1989b].

\section{SUMMARY}

An extensive side-by-side konimeter/gravimetric respirable silica-dust-sampling program was undertaken in gold and uranium mines in Ontario. The results enabled a conversion relationship to be established. The relation was nonlinear and may reflect the limitations of the konimeter in measuring high dust concentrations and of the gravimetric respirable sampler in measuring low dust concentrations. Different relationships were established for gold and uranium mines, and these may be due to different fractional silica concentrations in the host rock. No differences could be demonstrated in relation to specific underground mining tasks. The results were used to convert the mine's historical konimeter counts into gravimetric respirable silica equivalents. The cumulative respirable silica dose for each miner was then calculated by linking the year/mine/task gravimetric concentration with his detailed work history.

\section{ACKNOWLEDGMENTS}

The investigation was funded by the Ontario Mining Association, the Ministry of Labour of the Government of Ontario, and the Workers' Compensation Board of Ontario. Our thanks are for these agencies and for the support of the steering committee members.

Special acknowledgment is made to miners who participated in the investigations, to mine management, and to representatives of the United Steel Workers of America and the Union of Mine Mill and Smelter Workers at the mines where the investigations took place. Thanks are also due to Chris Jodouin, Craig McGinlay, Peter Petrikowski, Dan Lafortune, Mary Rogers, Henrik Vogt, Cath Martin, Sherry Kreig, Don Shaw, and Sharon Piedimonte for their help. 


\section{REFERENCES}

Aerosol Technology Committee (1970): Guide for respirable mass sampling. Am Ind Hyg Assoc J 31:133-137.

Ayer HE, Dement JM, Busch KA, Ashe HB, Levadie BTH, Burgess WA, DiBerardinis LJ (1973): A monumental study-reconstruction of a 1920 granite shed. Am Ind Hyg Assoc J 34:206-211.

Cartwright J (1965a): Relationships between mass and number concentrations of respirable airborne dust in British coal mines. Part 1: Mass-number relationships for coal-dust clouds. Ann Occup Hyg 8:193-206.

Cartwright J (1965b): Relationships between mass and number concentrations of respirable airborne dust in British coal mines. Part 2: Mass-number relationships for mixed clouds of coal and rock dust. Ann Occup Hyg 8:257-264.

Chmara P (1969): The electronic scanner-an instrument for rapid counting of dust spots. Can Min Met (CIM) Bull:1171-1174.

Chmara P, Knight G (1978): “A comparison of konimetry and gravimetric dust samplers.” Elliot Lake, Ontario: Mining Research Laboratories Report MRP/MRL 78-94 (TR).

Chamberlain EAC, Makower AD, Walton WH (1971): New gravimetric dust standards and sampling procedures for British coal mines. In Walton WH (ed): "Inhaled Particles, III (II).” Old Woking, Surrey: Unwin Bros., pp 1015-1030.

Checkoway H (1986): Methods of treatment of exposure data in occupational epidemiology. Med Lav 77:48-73.

Checkoway H (1987): Missing exposure data in occupational epidemiology. Presented at the Am Ind Hyg Assoc Conference, Montreal, Quebec, June 1987.

Corn M, Esmen NA (1979): Workplace exposure zones for classification of employee exposures to physical and chemical agents. Am Ind Hyg Assoc J 40:47-57.

Davis LK, Wegman DH, Monson RR, Froines J (1983): Mortality experience of Vermont granite workers. Am J Ind Med 4:705-723.

Dement JM, Harris RL, Symons MJ, Shy CM (1983): Exposure and mortality among chrysotile asbestos workers. Part I: Exposure estimates. Am J Ind Med 4:399-419.

Dodgson J, Whittaker W (1973): The determination of quartz in respirable dust samples by infrared spectrophotometry-I: The potassium bromide disc method. Ann Occup Hyg 16:373-387.

Dodgson J, Hadden GG, Jones CO, Walton WH (1971): Characteristics of the airborne dust in British coal mines. In Walton WH (ed): "Inhaled Particles III (II).” Old Woking, Surrey: Unwin Bros., pp 751-782.

Emmerichs M, Armbruster L (1981): "Weiterentwicklung eines Vielstufenimpaktors zur Bestimmung der Kornverteilung von luftgetragenen Stäuben.” Essen: Hauptstelle für Staubbekämpfung und Pneumokonioseverhütung des Steinkohlenbergbauvereins, Report No. 14/81, pp 111-115.

Flint TR (1965): Electronic particle counting. Can Min J:82-85.

Gibbs GW, LaChance M (1974): Dust-fiber relationships in the Quebec chrysotile industry. Arch Environ Health 28:69-71.

Hinds WC (1982): “Aerosol Technology-Properties, Behavior, and Measurement of Airborne Particles.” New York: John Wiley \& Sons, pp 69-103.

Jacobson M, Tomb TF (1967): Relationship between gravimetric respirable dust concentration and midget impinger number concentration. Am Ind Hyg Assoc J 28:554-556.

Jacobsen M, Rae S, Walton WH, Rogan JM (1971): The relation between pneumonoconiosis and dust exposure in British coal mines. In Walton WH (ed): "Inhaled Particles III (II).” Old Woking, Surrey: Unwin Bros., pp 903-919.

Kromhout H, Oostendorp Y, Heederik D, Boleij JSM (1987): Agreement between qualitative exposure estimates and quantitative exposure measurements. Am J Ind Med 12:551-562.

Lippmann M, Harris WB (1962): Size-selective samplers for estimating "respirable" dust concentrations. Health Phys 8:155-163.

Muir DCF, Shannon HS, Julian JA, Verma DK, Sebestyen A, Bernholz CD (1989a): Silica exposure and silicosis among Ontario hardrock miners: I. Methodology. Am J Ind Med. 16:5-11

Muir DCF, Julian JA, Shannon HS, Verma DK, Sebestyen A, Bernholz CD (1989b): Silica exposure and silicosis among Ontario hardrock miners: III. Analysis and risk estimates. Am J Ind Med. 16:29-43

NIOSH (1984): Silica, Crystalline (IR). Method \#7602. In Eller PM (ed): "NIOSH Manual of Analytical Meth- 
ods (3rd ed), Vol 2." Cincinnati, Ohio: US Dept. of Health and Human Services.

Rice C, Harris RL, Lumsden JC, Symons MJ (1984):Reconstruction of silica exposure in North Carolina dusty trades. Am Ind Hyg Assoc J 45:689-696.

Sebestyen A, Verma DK, Muir DCF (1987): An evaluation of konimeter performance-I. Determination of the particle acceptance curves of continuously aspirated konimeters using latex spheres. Ann Occup Hyg 31:441-449.

Sutton GW, Reno SJ (1968): Respirable mass concentration equivalent to impinger data: Barre, Vermont granite sheds. Presented at Annual Conference Am Ind Hyg Assoc, St. Louis, Mo.

Thériault GP, Burgess WA, DiBerardinis LJ, Peter JM (1974): Dust exposure in Vermont granite sheds. Arch Environ Health 28:12-17.

van Neirop JA (1973): Routine dust sampling. J Mine Vent Soc S Afr 26:101-112.

Verma DK, Sebestyen A, Muir DCF (1987): An evaluation of konimeter performance-II. A field comparison of konimeters. Ann Occup Hyg 31:451-461.

Walton WH (1982): The nature, hazards and assessment of occupational exposure to airborne asbestos dust: A review. Ann Occup Hyg 25:117-247.

\section{APPENDIX}

TABLE A. Table of Conversion Based on the Gravimetric to Konimeter Equation $\left(K=\beta_{0} \cdot\left(1-\exp \left(\beta_{1} \cdot G\right)\right)+\beta_{2} \cdot G\right)$ for Two Ore Types, Using the Parameter Estimates Given in Table II.

\begin{tabular}{|c|c|c|}
\hline \multirow[b]{2}{*}{ Respirable silica $\left(\mathrm{mg} / \mathrm{m}^{3}\right)$} & \multicolumn{2}{|c|}{ Konimeter count (ppcc) } \\
\hline & Gold & Uranium \\
\hline 0.00 & 0 & 0 \\
\hline 0.01 & 112 & 39 \\
\hline 0.02 & 197 & 76 \\
\hline 0.03 & 262 & 108 \\
\hline 0.04 & 312 & 139 \\
\hline 0.05 & 350 & 166 \\
\hline 0.06 & 380 & 191 \\
\hline 0.07 & 403 & 214 \\
\hline 0.08 & 420 & 235 \\
\hline 0.09 & 434 & 255 \\
\hline 0.10 & 445 & 272 \\
\hline 0.11 & 454 & 289 \\
\hline 0.12 & 461 & 303 \\
\hline 0.13 & 467 & 317 \\
\hline 0.14 & 471 & 329 \\
\hline 0.15 & 475 & 341 \\
\hline 0.16 & 479 & 351 \\
\hline 0.17 & 482 & 361 \\
\hline 0.18 & 484 & 370 \\
\hline 0.19 & 487 & 378 \\
\hline 0.20 & 489 & 386 \\
\hline 0.30 & 507 & 436 \\
\hline 0.40 & 523 & 461 \\
\hline 0.50 & 538 & 476 \\
\hline 0.60 & 554 & 487 \\
\hline 0.70 & 570 & 497 \\
\hline 0.80 & 586 & 506 \\
\hline 0.90 & 602 & 515 \\
\hline 1.00 & 618 & 523 \\
\hline 2.00 & 777 & 610 \\
\hline 3.00 & 936 & 696 \\
\hline 4.00 & 1095 & 782 \\
\hline 5.00 & 1254 & 869 \\
\hline
\end{tabular}

